\title{
Funding assured for international malaria sequencing project
}

[PARIS] Britain's Wellcome Trust last week gave a much-needed boost to malaria research with a decision to invest $\mathfrak{E} 8$ million in an international effort to sequence the genome of Plasmodium falciparum, the deadliest malaria parasite.

The three-year Wellcome Trust grant alone meets more than half the estimated \$20 million costs of the international project to sequence the 30 megabase genome of $P$. falciparum, and means that the project is now guaranteed to go ahead.

The grant is also substantial in terms of overall funding for malaria research, which amounts to only around $\$ 100$ million annually (see Nature 386, 539; 1997).

The decision comes 100 years, almost to the day, after Ronald Ross, a British physician, discovered the role of the mosquito in the parasite lifecycle. To celebrate the anniversary, more than 650 researchers, public health officials and funding agencies are meeting this week in Hyderabad, India.

"The grant is a very big boost to the entire malaria field," says Dyann Wirth, a molecular parasitologist at Harvard School of Public Health who chairs the World Health Organization committee on malaria drugs. Malaria kills more than a million people every year.

The P.falciparum genome project is being coordinated by an international consortium, each body managing its own funds independently. Most of the sequencing work is to be carried out at the US Institute for Genome

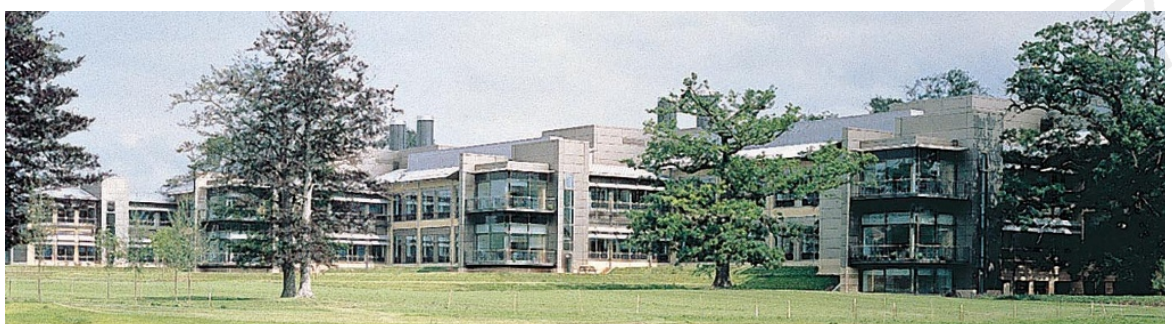

The Sanger Centre: part of the consortium sequencing the genome of malaria parasite $P$. falciparum.

Research (TIGR), and the Sanger Centre at the Wellcome Trust's genome campus at Hinxton near Cambridge, England. Other participating institutes include the Naval Medical Research Institute (NMRI) in Rockville, Maryland, Stanford University, Harvard University, and Oxford's Institute of Molecular Medicine.

In addition to the $£ 8$ million grant from Wellcome, the US Department of Defense plans to invest $\$ 8$ million, while the Burroughs Wellcome fund has made a grant of $\$ 2.5$ million. The US National Institute of Allergy and Infectious Diseases (NIAID) has granted \$1 million to support pilot projects at TIGR and NMRI, and hopes to invest a further $\$ 2$ to $\$ 3$ million.

Each of the 14 chromosomes of P. falciparum has been assigned to an individual participant, and the genome is expected to be completely sequenced within three years. Initial funding has supported pilot projects aimed at developing techniques suited to the

\section{Europe's poorer regions woo researchers}

[MUNICH] An initiative to encourage holders of 'trans-European' research fellowships to join industrial laboratories and laboratories in poorer regions of Europe is being backed by the European Commission (EC).

The Potential Host Institutes List (PHIL) has been set up so that laboratories can advertise their readiness to take young Marie Curie research fellows, who receive EC grants to work in European Union (EU) countries other than their own. The list is published on the World-Wide Web.

The initiative is an attempt to correct the uneven distribution of Marie Curie fellowships. The holders of one-third of the 2,200 fellowships awarded between 1992 and 1996 under the EC's Human Capital and Mobility Programme and its successor, the Training and Mobility of Researchers Programme, chose to work in Britain, a quarter in France, and 11 per cent in the Netherlands and Belgium.
In contrast, only 10 per cent went to Germany, and more peripheral EU countries were rarely chosen. Also, despite the EC's efforts to promote industrially relevant research, only two per cent of fellowship holders chose industrial host institutes.

The prime factor influencing the geographical distribution of host institutes appears to be the strengt of research in central northern European countries. Germany's relative unpopularity is attributed to the perceived difficulty of the German language, as well as the continuing historical burden of the Nazi era.

Although the EC would like to see a more even spread, it is at present restricting support for PHIL to two of its political priority areas: industry and less-privileged EU countries. It will assess the effectiveness of the advertising of potential host institutes after the next deadline for applications in mid-September.
$P$. falciparum genome, which is unusually high in adenine and thymine, two of the four nucleotides, or building blocks, that make up DNA. Sequencing of chromosomes 2 and 3, P. falciparum's smallest chromosomes, have almost been completed in pilot projects at the TIGR and the Sanger Centre respectively.

The main immediate impact of the genome project is likely to be the discovery of new targets for drugs. Widespread resistance of the parasite to available drugs is emerging and research by the pharmaceutical industry to develop new families of drug has been all but abandoned (see Nature 386, 540; 1997). Tim Stanley from Glaxo-Wellcome's malaria programme says the genome project "could open up 10 or 20 new families of drug".

The Wellcome Trust's decision marks a shift towards putting genome research at the heart of its infectious diseases programmes. To test the feasibility, the trust last year set up a Pathogen Genome Sequencing Centre at the Sanger Centre, choosing as pilot projects the bacterium Mycobacterium tuberculosis and chromosome 3 of $P$. falciparum.

The experience has convinced the trust that genome research is the most "cost-effective" means to support research in infectious diseases, says John Stephenson, the scientific programme manager, because it provides fundamental information for the global research community. "Genomics is going to change the whole way in which infectious disease research is done," says Stephenson.

Louis Miller, head of the Laboratory of Parasitic Diseases at NIAID, agrees. "For example, if we knew what molecule told the parasite it had hit a red cell, we could make a vaccine against it," he says. "By sequencing the parasite's entire genome, we will be able to identify the signalling genes involved in the recognition process."

But Adrian Hill, malaria vaccine researcher at the University of Oxford, argues that while genome research will provide new candidate antigens relevant to malaria in the medium term, the bottleneck in vaccine research remains the lack of funds for clinical trials of existing antigens.

DeclanButler 